\title{
The worthiness of using information on land-use-land-cover in watershed models for Western Ghats: A case study
}

\author{
Mysuru R Yadupathi Putty ${ }^{1, *}$ and B M Kavya ${ }^{2}$ \\ ${ }^{1}$ The National Institute of Engineering, Mysuru, Karnataka 570 008, India. \\ ${ }^{2}$ BGSIT, Bellur, Mandya District, Karnataka 571 448, India. \\ ${ }^{*}$ Corresponding author. e-mail: puttyyadupathi@gmail.com
}

MS received 26 October 2017; revised 11 January 2018; accepted 30 January 2018; published online 20 November 2018

The variable source area (VSA) theory of runoff generation mechanisms has been proved to hold good in many wet mountainous areas, decades ago. According to this theory, infiltration-excess overland flow is limited to very small areas in mountainous and forested catchments. But, the perception that the land surface characteristics, including land-use-land-cover (LULC), form the major factors influencing the response of the catchment to rainfall has dominated the thought in hydrology to such an extent that models based on the overland flow theory continue to be used even in such areas. The present study was taken up in order to understand the worthiness of using parameters, including the curve number $(\mathrm{CN})$, that are based on the physiographic characteristics of the catchment in a watershed model designed to estimate runoff in the wet mountainous areas of the Western Ghats in southern India, where the VSA theory has been proved to hold good. The study has been accomplished by applying the NITK model developed for estimating runoff using daily rainfall data. This model is believed to estimate reliably the streamflow in the region using parameter values that can be computed from catchment characteristics. In the present study, it is applied on three gauged streams in the region of Western Ghats in Karnataka. Initially, the performance of the model has been studied with the parameters fixed using the catchment characteristics. Later, the model has been used as a tool to test hypotheses concerning the catchment response, by varying the parameter values, adopting a trial and error procedure. Initial results showed that the model performance is poor as the coefficients of efficiency vary between -66.9 and $82 \%$. The sensitivity analysis carried out subsequently showed that the model parameters are required to be altered greatly for good performance and that the model simulations are not sensitive to the parameter CN. Further, the performance of this model was compared with that of a VSA model, known to suit the region well. This showed that even after all the changes in the model parameters, the model results are not highly reliable. Hence, in order to understand the reasons for the poor performance of the model, a technique was developed to compute the $\mathrm{CN}$ values that would be actually necessary to simulate daily direct runoff (DRO) reliably in this method, the daily values of CN are computed by applying backwards the expression for runoff on the DRO estimated by the VSA model. The variations in the values of CN computed using this method are then studied. It is found that the variations in daily $\mathrm{CN}$ are high and highly random too, whereas the NITK model uses only three fixed values of CN. It is thus concluded that factors other than those on which the $\mathrm{CN}$ is popularly believed to depend control the runoff generation in the region and that influence of LULC on runoff is not discernible at all from the kind of data that is commonly available.

Keywords. Curve number method; variable source area theory; streamflow components; influence of LULC; curve number and contributing area. 


\section{Introduction}

Most of the fundamental design methodologies in hydrology are based on the relationship between rainfall and its response. The general perception is that the response is strongly influenced by the physiographic characteristics of the catchment, including land-use and land-cover (LULC). Hence, many hydrological models use the data on catchment characteristics as input. The Curve Number (CN) method is one example of the models that use LULC data for estimation of runoff from rainfall in ungauged catchments. This method has gained popularity in India because of its simplicity (Chow et al. 1988; Subramanya 2013) and its applicability on daily rainfall data (CUSU 1972). It is also more versatile than the earlier models, while the models used prior to the $\mathrm{CN}$ method considered just three or four types of catchment conditions (like good, bad and normal), the $\mathrm{CN}$ method specifies more than a hundred sets of soil-LULC classes and assigns CN for each of them. However, the CN method is a device for estimating only the Hortonian surface runoff (Ward 1984). But, in many mountainous and forested areas, the Hortonian type overland flow is not dominant. According to the variable source area (VSA) theory (Hewlett and Hibbert 1967), in such areas, subsurface runoff also contributes significantly to the streamflow. So, in such areas, there have been attempts to modify the CN method by modeling baseflow separately and combining this component with the surface runoff component. Still, the reliance on the LULC as a control to estimate the model parameters continues to persist, even though subsurface flow usually is not influenced by LULC. There have been many evidences to show that the runoff mechanisms in the Western Ghats area in the state of Karnataka, in south India, are also well explained by the VSA theory (Putty and Prasad 1992, 2000a). Hence, there is a doubt whether the models found on the principle of the CN method perform well in estimating runoff in these areas. The present study was taken up to investigate the extent to which the use of the principle of $\mathrm{CN}$ method is beneficial in runoff models for this region. Hence, this study can be considered as an attempt to find out the worthiness of using LULC as a parameter in the relationship between rainfall and runoff in catchment areas, where subsurface runoff is an important component of streamflow.

Many studies have been carried out on the data from the Western Ghats region using models developed on the basis of the CN method. Putty et al. (1996) showed that the simple CN method estimates much lower values of runoff than the observed in this region. Mishra and Singh (1999) applied a modified form of the $\mathrm{CN}$ method on the catchment of Hemavathi in this region and found that the method performs well in estimating the direct runoff from the basin after baseflow separation. But, even though baseflow forms a dominant component of streamflow (Putty and Prasad 2000a), Mishra and Singh (1999) do not furnish a methodology for estimating it. Mishra (1998) presented a two component model based on the CN method for continuous simulation of daily streamflow. This model included a method to estimate baseflow also. Mishra (2000) improved this model by using the continuously varying $\mathrm{CN}$ principle, developed by Hawkins (1978) for estimating the direct runoff component. He has shown that this model performs much better than the commonly used model in which only three values of $\mathrm{CN}$ (Chow et al. 1988) are used. He has also found that the CN varies from near zero values up to 100, in the case of the catchment of Hemavathi. Geetha et al. (2008) have developed a three component model, which includes a part of deep percolation and showed that this model performs better than the earlier ones (Putty and Prasad 2000a; Mishra et al. 2005). Putty (2009) has presented a variable source area model, in which the CN method is used as a means for estimating pipe flow (Putty and Prasad 2000b). However, all these models are lumped parametric models containing a number of parameters, which need to be optimized using records of streamflow data. Hence, they cannot be applied on ungauged basins.

Nandagiri et al. (2004) present a two component model with 'identifiable parameters', useful for prediction in ungauged basins. This is a modified version of the earlier KREC Model (Version 2) developed by Nandagiri (2002). Termed the NITK model, this contains four parameters, which can all be estimated a priori, based on a knowledge of the LULC, the soil type and the topographic characteristics of the basin. The KREC model (Version 2) has been applied to the gauged Gurpur River basin $\left(841 \mathrm{~km}^{2}\right)$ and the NITK model has been applied on the data from catchment of Yenne Hole $\left(327 \mathrm{~km}^{2}\right)$, located in the Dakshina Kannada and Udupi districts of Karnataka in India, respectively. These models have been found to be well suited for application for prediction in the ungauged basins of the region. In fact, KREC model (Version 2) is 
one of the models quoted by the Central Water Commission (CWC 2010) in its 'state of the art report' and hence can be considered to be the one accepted for general application for estimation of runoff. Hence, the present work is carried out using the NITK model developed by Nandagiri et al. (2004). This model can be used to estimate daily runoff from ungauged catchments. However, in the present study, the model is used as a tool for testing hypotheses (Ward 1983) concerning the fundamental assumptions in the model, by applying it on catchments which have been gauged and the records have been found to be reliable. These records have earlier been used for studying the catchment response to rainfall in the region (Putty and Prasad 2000a) with good results. Hence, these data and results form a basis for drawing inferences regarding the simulations of the NITK model.

\section{The study area and the data used}

The study pertains to the central Western Ghats area spread over the western parts of Karnataka, bordering the coast (figure 1). This region, characterized by a highly mountainous terrain, with a dense vegetation cover and very heavy rainfall, forms the life-line of the state of Karnataka, supplying more than $75 \%$ of its surface waters (Prasad and Malhotra 1987). The present study has been accomplished by using records from the catchments of Malathi $\left(260 \mathrm{~km}^{2}\right)$, Hemavathi $\left(600 \mathrm{~km}^{2}\right)$ and Netravathi $\left(3087 \mathrm{~km}^{2}\right)$, lying between the north latitudes $11^{\circ} 30^{\prime}$ and $14^{\circ} 30^{\prime}$ (figure 1). Since this paper also refers to the results of studies carried out over a long period (Putty and Prasad 2000a; Putty et al. 2007; Putty 2009), the records used pertain to different periods of time for the different catchments. However, in each case, five years' records of daily streamflow and daily rainfall of the monsoon months (June-September), made available by the user agencies, are used. The details concerning the catchments and the data used, are presented in table 1.

\section{The NITK model}

This lumped basin-scale water balance model, based on Thornthwaite-Mather water balance accounting procedure was developed by Nandagiri et al. (2004). The model utilises inputs of daily

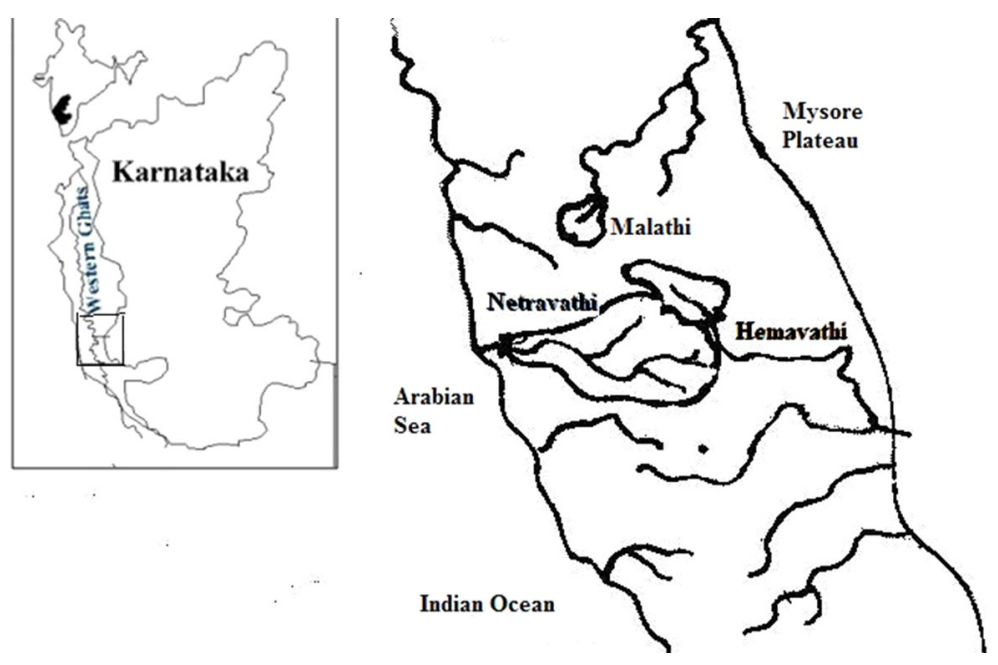

Figure 1. Location of the catchments studied.

Table 1. Details concerning the data used.

\begin{tabular}{lcccccc}
\hline Catchment & $\begin{array}{c}\text { Area } \\
\left(\mathrm{km}^{2}\right)\end{array}$ & $\begin{array}{c}\text { No. rain } \\
\text { stations }\end{array}$ & Data/years & $\begin{array}{l}\text { NRF } \\
(\mathrm{mm})\end{array}$ & $\begin{array}{l}\text { MRO } \\
(\mathrm{mm})\end{array}$ & Data source \\
\hline Malathi & 266 & 5 & $1976-81$ & 5660 & 4701 & WRDO/DES \\
Hemavathi & 600 & 6 & $1976-81$ & 2888 & 1959 & WRDO/DES \\
Netravathi & 3187 & 10 & $1981-85$ & 3300 & 3582 & CWC/DES \\
\hline
\end{tabular}

NRF: Normal annual rainfall, MRO: Monsoon runoff, CWC: Central Water Commission, WRDO: Water Resources Development Organisation, Karnataka WR Dept., DES: Karnataka Directorate of Economics and Statistics, Bengaluru. 
rainfall (RF) and potential evapotranspiration (PET) and gives continuous output of direct runoff, groundwater recharge, baseflow, actual evapotranspiration and total runoff. According to this model, the streamflow comprises of two components, direct runoff and baseflow. Further, the catchment is supposed to consist of two subsurface zones, the unsaturated soil zone and the saturated ground water zone. The algorithm of the model is given below:

1. Rainfall on the catchment, after initial abstraction $(I a)$, gets divided into two parts: direct runoff (DRO) and infiltration (INFL). DRO from precipitation is computed using the SCS-CN approach as:

$$
\mathrm{DRO}=(R F-0.3 S)^{2} /(R F+0.7 S)
$$

where $R F$ is the rainfall and $S$ is the potential infiltration, obtained from the $\mathrm{CN}$ for the day.

2. Rainfall in excess of $I a$ and DRO goes down into the unsaturated top subsurface zone as infiltration (INFL). Hence,

$$
\mathrm{INFL}=R F-I a-\mathrm{DRO} .
$$

$I a$ is taken equal to $0.3(S)$. The INFL adds to the soil moisture store in the unsaturated zone.

3. Evapotranspiration occurs from the soil moisture store whenever the storage in this zone $(\mathrm{SM})$ is greater than the wilting point (PWP). Actual evapotranspiration depends on SM. It will be equal to the potential value for the crop (CET) whenever SM is equal to or greater than the available water content (AWC), which is equal to the difference between field capacity (FC) and the wilting point (PWP) for the soil. Crop potential evapotranspiration is calculated from the available data on reference crop evapotranspiration (PET) for the region, using the crop coefficient $k_{c}$, as

$$
\mathrm{CET}=k_{c} \cdot(\mathrm{PET}) .
$$

When SM is less than AWC, actual evapotranspiration (AET) is calculated as:

$$
\mathrm{AET}=(\mathrm{SM}) \cdot(\mathrm{CET}) /(\mathrm{AWC}) .
$$

Further, when SM is greater than FC, water percolates down and results in ground water recharge (GWR). Thus,

$$
\mathrm{GWR}=\mathrm{SM}-\mathrm{FC} .
$$

GWR feeds the saturated ground water zone. The storage in this zone is denoted as GWS.

4. Baseflow (BF) for any day is calculated using the function

$$
\mathrm{BF}=(1-\mathrm{BLAG}) \cdot(\mathrm{GWS})
$$

where BLAG is a parameter called baseflow lag coefficient.

5. Total runoff (TRO) for the day is computed as

$$
\mathrm{TRO}=\mathrm{DRO}+\mathrm{BF} .
$$

Soil moisture content (SM) and the ground water storage (GWS) for any day are computed using the water balance equations, given by

$$
\begin{aligned}
& \mathrm{SM}_{i+1}=\mathrm{SM}_{i}+\mathrm{INFL}_{i}-\mathrm{AET}_{i}-\mathrm{GWR}_{i} . \\
& \mathrm{GWS}_{i+1}=\mathrm{GWS}_{i}+\mathrm{GWR}_{i}-\mathrm{BF}_{i} .
\end{aligned}
$$

\subsection{Model parameters}

The NITK model has four parameters: the curve number $(\mathrm{CN})$, the permanent wilting point $(\mathrm{PWP})$, the field capacity (FC) and baseflow lag coefficient (BLAG). For application of the model on ungauged catchments, these parameters need to be determined a priori by using information from the toposheets, satellite imageries or other maps. $\mathrm{CN}$, which is based on LULC and the soil type, can be readily obtained from standard tables published in the literature. The PWP and FC may be derived from published data on soil hydraulic properties for various soil textural types and using the information furnished by Putty and Prasad (2000b) and by Nandagiri and Shetty (2009). The parameter BLAG is estimated using the relationships presented by Mohan and Nair (1986), using information on basin slope, soil type and extent and type of forest cover. The parameters of the model for the catchments considered in the present study have been obtained using information from the following sources:

- RS imageries supplied by ISRO and topomaps of the Survey of India, and

- Soil maps of NBSSLUP, Bengaluru, and the French Institute, Puduchery (Borugeon 1989). 


\section{Methodology}

The aim of the present study is to understand the extent to which the use of correct information on LULC would improve simulation abilities of rainfall-runoff models. For this purpose, the NITK model is applied on three catchments for which reliable runoff values are available. The methodology used in this work consists of the following steps:

1. Application of the model as on ungauged catchments: In this step, the model parameters are estimated a priori using data on LULC and other catchment characteristics derived from maps and imageries. The runoff values estimated by the model are then compared with the observed values.

2. Parameter optimization and sensitivity analysis: Optimization is a technique used to find out the parameter values which estimate the output to nearest possible to the observed values. Sensitivity analysis, on the other hand, helps understand the relative importance of the various parameters in the model. In this second step of the present work, the NITK model is considered as a conceptual parameter model and the model parameters are optimized using the observed runoff data. Also, the model is modified a little to accommodate temporally varying values of $\mathrm{CN}$. Then, the performance of the model with optimized parameters and temporally varying $\mathrm{CN}$ values is tested. A sensitivity analysis is carried out to determine the effect of varying the value of the different parameters on the simulations.

3. Comparison with another model: In this step, the performance of the NITK model with a few small modifications is compared with that of the model SAHYADRI, developed by Putty (1994). Putty and Prasad (2000a) have established this model to be a good tool for analyzing records in this region. Then, the continuous variation in $\mathrm{CN}$ values required to match the performance of SAHYADRI is established by applying the runoff expression of the CN method backwards. The pattern of variation in $\mathrm{CN}$ so obtained is analysed to infer on the worthiness of using LULC data in the models for the region.

\subsection{Tests for the model performance}

Since the intention of the present study is to test the validity of the assumptions of the NITK model, the runoff simulations of this model are to be compared with the observed runoff. Further, the performance of the model is compared with that of the model SAHYADRI. For accomplishing this task of testing and comparing the model performance, the following commonly used graphical and analytical tests (Aitken 1973; Putty 2010) are adopted:

1. Graphical tests: They include plotting (a) scatter diagrams of estimated runoff against observed runoff and (b) matching hydrographs, where hydrographs of estimated runoff and observed runoff are plotted on the same sheet for being visually compared;

2. Analytical test: This comprises of estimating the Nash-Sutcliffe coefficient of efficiency (Aitken 1973). Coefficient of efficiency (CE) is defined as the ratio of variation in the data explained by the model to the total variation present in the data. It is given by the formula

$$
\mathrm{CE}=1-\left[\Sigma\left(Q_{0}-Q_{e}\right)^{2} / \Sigma\left(Q_{0}-Q_{\text {mean }}\right)^{2}\right]
$$

where $Q_{0}=$ observed runoff, $Q_{e}=$ estimated runoff corresponding to $Q_{0}$ and $Q_{\text {mean }}=$ mean of the observed runoff values.

The common practice of studying the performance of a model consists of calibrating the model using one part of the available data and using the other part for validating the simulations. This is known as the 'split record' procedure. In the present study also, this procedure is adopted in the second part of the work, where the NITK model is used as a parametric model, requiring parameter optimization. Here, the records of only the first two years are used for calibrating the model and for illustrating the results. However, the complete length of the records are used while arriving at the final conclusions.

\section{The initial results}

As explained in the methodology section, the NITK model was first applied on the catchments by using the lumped parameter values estimated $a$ priori. The parameters were estimated in accordance with the method outlined by Nandagiri and Shetty (2009), using the relevant maps and $\mathrm{RS}$ imageries. The LULC details for the catchments used in computation of $\mathrm{CN}$ are shown in 
(a)

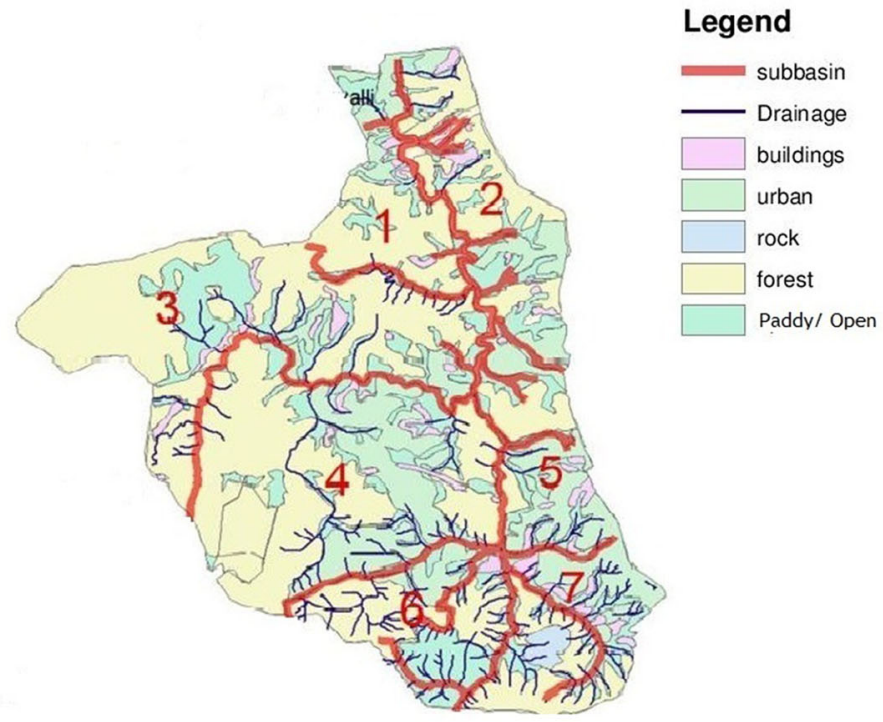

(b)

Legend
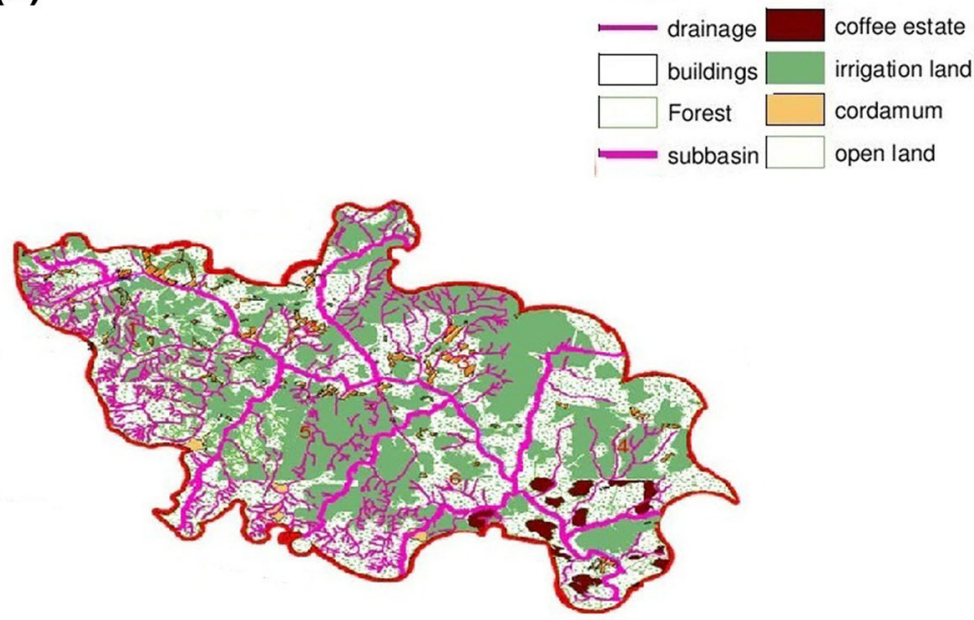

(c)

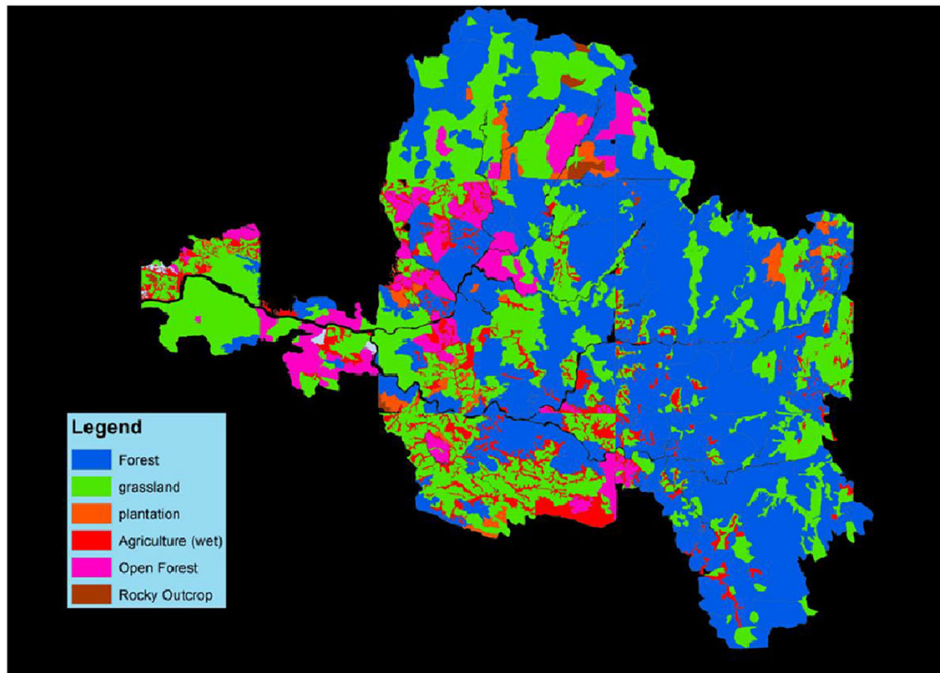

Figure 2. Details of LULC in the catchments of (a) Malathi, (b) Hemavathi, and (c) Netravathi, considered in computation of $\mathrm{CN}$. 
Table 2. Parameter values used to run the NITK model.

\begin{tabular}{llll}
\hline Parameters & Malathi & Hemavathi & Netravathi \\
\hline Field capacity of the soil (FC) & 0.26 & 0.26 & 0.26 \\
Wilting point of the soil (PWP) & 0.18 & 0.18 & 0.18 \\
Effective root zone depth (z) & 1.1 & 1.1 & 1.1 \\
Curve number (CN) & 65 & 60 & 60 \\
Base flow lag coefficient (BLAG) & 0.405 & 0.51 & 0.50 \\
\hline
\end{tabular}

figure 2. The parameter values adopted for the three catchments are shown in table 2 .

The results of the tests of performance of the model for the first two years are presented in the following illustrations:

- figure 3: scatter diagrams comparing the estimated values with the observed;

- figure 4: a few cases hydrograph comparisons;

- table 3: the values of the coefficient of efficiency.

It is evident from a study of these illustrations that the simulations of the NITK model cannot be considered reliable. Since the parameters of the model used are not those optimized, the simulations cannot be expected to be very good. But, the fact that even the 10-day simulations are very poor goes to show that either the parameter values or the model structure is not acceptable. A parameter sensitivity analysis after incorporation of small changes in the model structure can be expected to reveal the factors leading to such low simulating abilities of the model. The following is an attempt in this direction.

\section{Parameter optimization and sensitivity analysis}

Parameter optimization can be done either automatically using an objective best fit criterion or by the trial and error eye-balling technique (Anderson and Burt 1985; Putty 2010). The latter method, in which, the two steps of parameter optimization and sensitivity analysis can be accomplished together, has been followed in the present work. This procedure consists of running the model on the data using a number of different sets of parameter values and testing the model performance under each case. A discussion of the experiences from such a study is presented below.
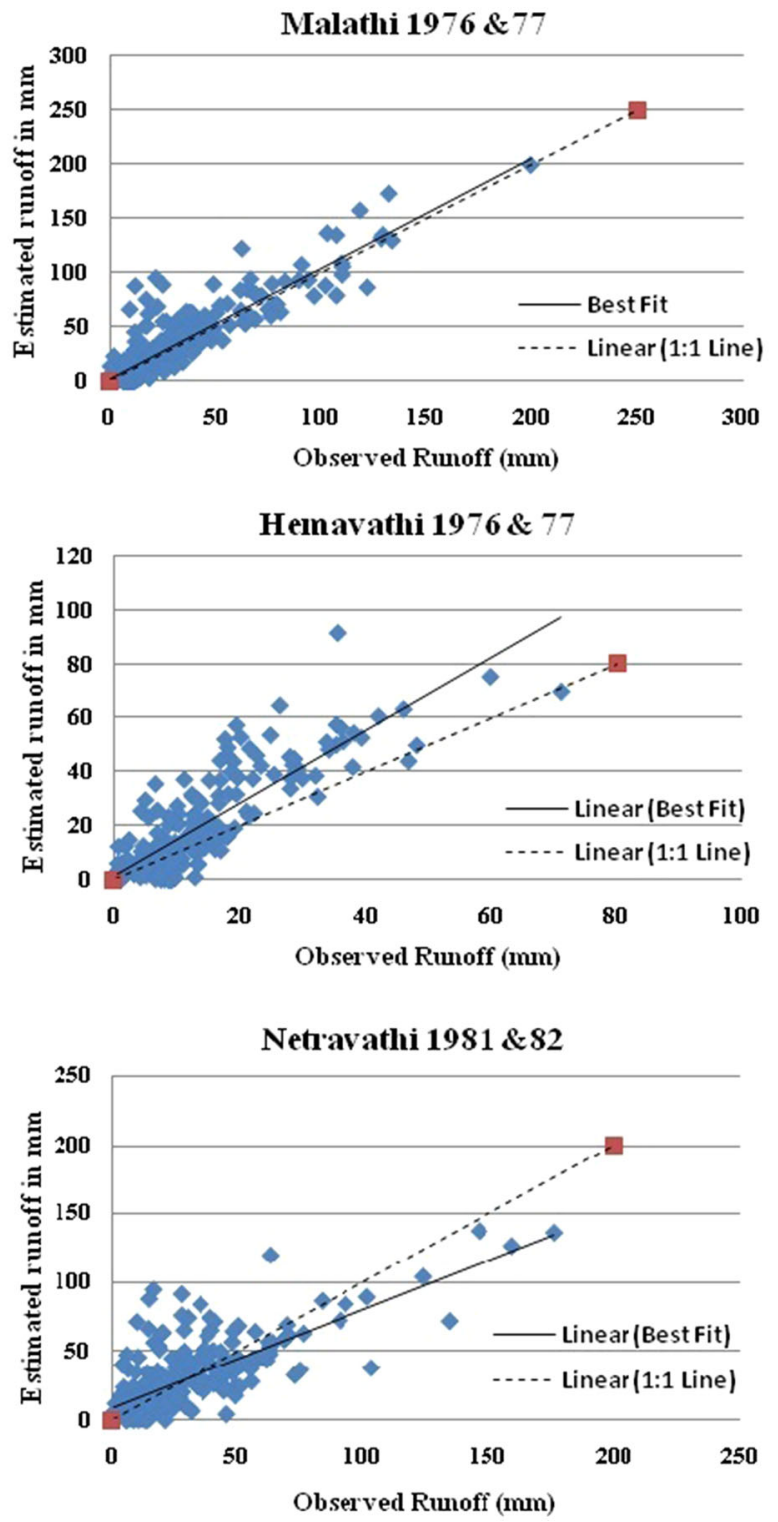

Figure 3. Scatter diagrams for testing the model performance with parameter values fixed a priori.

\subsection{The abstraction coefficient}

In the CN method, initial abstraction $(I a)$ is calculated from $S$ as $I a=C \cdot S$. The coefficient $(C)$ is usually called the abstraction coefficient. Even 

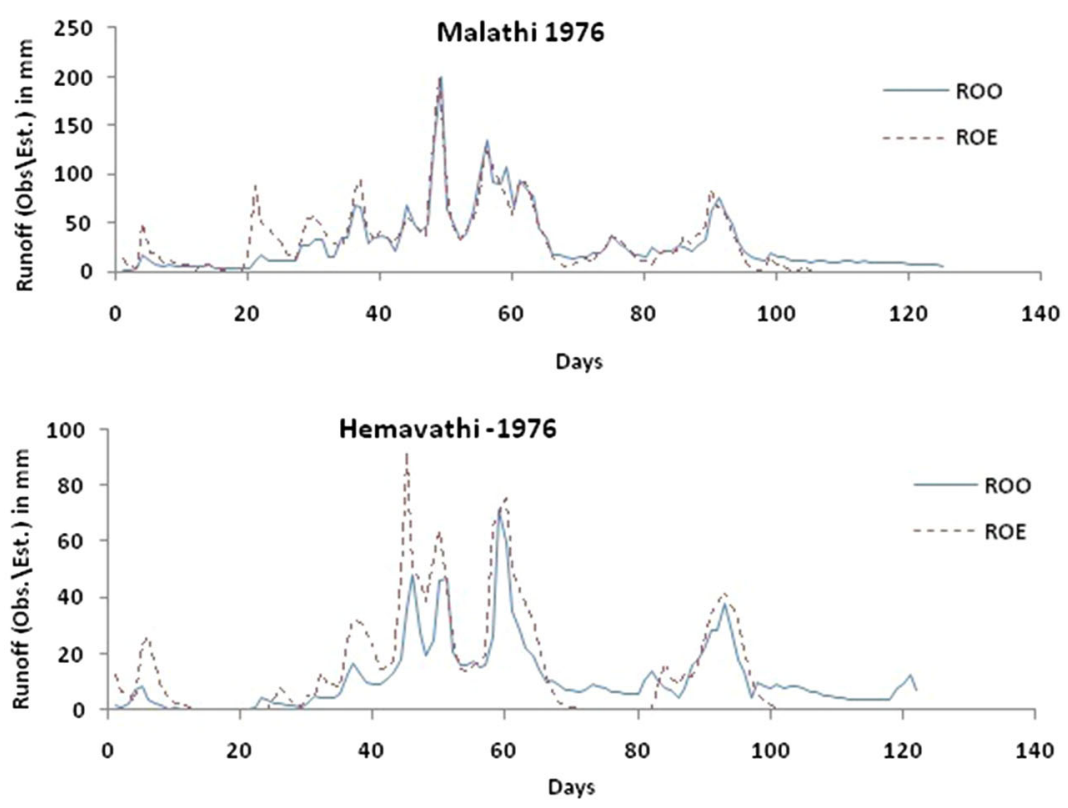

Netravathi 1981

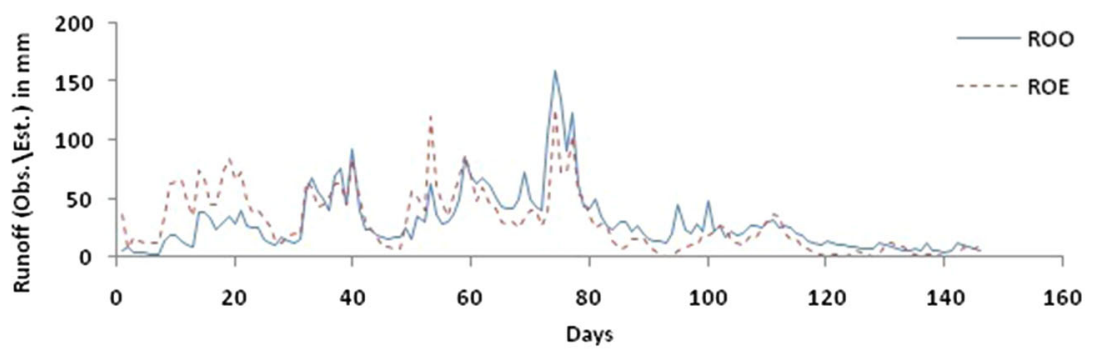

Figure 4. Comparison of hydrographs for testing the performance of the NITK model under parameters fixed $a$ priori.

Table 3. Performance of the NITK model under parameters estimated a priori.

\begin{tabular}{lcccccc}
\hline & \multicolumn{3}{c}{ Catchments } \\
\cline { 2 - 6 } CE & Malathi & Malathi & Hemavathi & Hemavathi & Netravathi & Netravathi \\
1982 & 1981 & 47.5 & 52.9 \\
\hline Coeff. of efficiency (CE) & 1976 & 1977 & 1976 & 25.5 & -66.9 & 47.9 \\
CE for 10-day sums & 82.0 & 63.0 & 34.0 & -79.7 & 48.2 & 49.0 \\
\hline
\end{tabular}

though $C$ is taken as 0.3 in the NITK model, generally different values of $C$ are used in different cases (Chow et al. 1988). Hence, the value of $C$ is first optimized in this work. The trial and error studies carried out for this purpose show that the model performs better with $C$ equal to 0.1 in case of Hemavathi and 0.3 in the other two cases. Hence, these values of $C$ are used for all further work in this paper.

\subsection{Optimizing BLAG}

It is known from investigations reported previously (Putty and Prasad 2000a; Putty 2009) that delayed flow is the predominant component of streamflow in the region of Western Ghats. Further, the hydrographs of streamflow simulated by the NITK model (figure 4) show that the errors during the drier part of the season are systematic. Hence, sensitivity analysis of the parameter associated with delayed flow (BLAG) is taken up first. Table 4 shows some sample results. It is evident from the table that values of BLAG much higher than those estimated a priori are necessary. This is not strange as the Western Ghats catchments are characterized by exceptionally thick soil mantles (Darshan 2016), up to $50 \mathrm{~m}$ in some areas, and thus have an ability to store huge quantities 
Table 4. Optimizing BLAG.

\begin{tabular}{lccccc}
\hline & \multicolumn{5}{c}{ Parameters } \\
\cline { 2 - 6 } Catchments & CN & C & BLAG & daily & 10-daily \\
\hline Malathi 1976 & 65 & 0.3 & 0.6 & 84 & 85 \\
& 65 & 0.3 & 0.8 & 87 & 89 \\
& 65 & 0.3 & 0.9 & 87 & 93 \\
Hemavathi 1976 & 65 & 0.3 & 0.95 & 85 & 92 \\
& 60 & 0.1 & 0.5 & 16 & 29 \\
& 60 & 0.1 & 0.6 & 22 & 32 \\
& 60 & 0.1 & 0.8 & 34 & 50 \\
Netravathi 1981 & 60 & 0.1 & 0.9 & 47 & 73 \\
& 65 & 0.3 & 0.7 & 51 & 90 \\
& 65 & 0.3 & 0.9 & 61 & 43 \\
& 65 & 0.3 & 0.95 & 64 & 73 \\
\hline
\end{tabular}

Table 5. Values of $C N$ varied over the monsoon according to the requirements.

\begin{tabular}{lccc}
\hline Period $($ days $*)$ & Malathi & Hemavathi & Netravathi \\
\hline $1-15$ & 60 & 60 & 50 \\
$16-31$ & 50 & 40 & 65 \\
$32-47$ & 80 & 35 & 70 \\
$48-63$ & 82 & 60 & 60 \\
$64-79$ & 90 & 30 & 70 \\
$80-95$ & 88 & 35 & 70 \\
$96-111$ & 80 & 50 & 70 \\
$112-127$ & 90 & 45 & 65 \\
\hline
\end{tabular}

*: Day no. start with June 1.

of water. The further work explained below was accomplished using BLAG equal to 0.95 for all the three catchments.

\subsection{Influence of $C N$ on simulations}

In order to estimate the most suitable values of $\mathrm{CN}$, a number of trial runs were carried out, varying the $\mathrm{CN}$ over the complete range is comprehendible.
The results were similar and complimentary to the conclusions of Nandagiri et al. (2004) that the model simulations are not very sensitive to the changes in the values of $\mathrm{CN}$. It was also evident that values of $\mathrm{CN}$ varying over time within the season would be necessary for a fairly good simulation of the catchment response. Hence, it was decided to divide the monsoon season into fortnightly periods and use different values of $\mathrm{CN}$ for the different periods. The most suitable $\mathrm{CN}$ value for each fortnight was individually arrived at by applying the procedure of trial and error on the corresponding data. The $\mathrm{CN}$ values so found out are presented in table 5 and the corresponding $\mathrm{CE}$ values are presented in table 6 . As seen in table 5, the $\mathrm{CN}$ values required to produce good results vary over a wide range, similar to the conclusions of Mishra (2000).

\section{A comparison with the performance of model SAHYADRI}

The modifications to the model suggested above have been based on the studies on data of the first two years that are reserved for model calibration, in each case. As explained, the model performance was found to get enhanced significantly with these modifications. Hence, it was decided to test the performance of the modified model using the data also of the second part, which has been reserved for validation. The results are presented in table 7 . This table shows the values of the $\mathrm{CE}$ (yearwise) for the modified NITK model compared with CE for the model SAHYADRI, reported by the earlier workers (Putty and Prasad 2000a; Putty et al. 2007). It is evident from the table that even with sets of varying $\mathrm{CN}$, the simulation ability of the NITK model does not match with that of SAHYADRI. Hence, in order to find out the possible reasons for the discrepancies in the simulation, the hydrographs estimated by the two

Table 6. Model performance with varying $C N$ values.

\begin{tabular}{|c|c|c|c|c|c|c|}
\hline \multirow[b]{2}{*}{ Parameters } & \multicolumn{6}{|c|}{ Catchments } \\
\hline & \multicolumn{2}{|c|}{ Malathi } & \multicolumn{2}{|c|}{ Hemavathi } & \multicolumn{2}{|c|}{ Netravathi } \\
\hline $\mathrm{CN}$ & \multicolumn{2}{|c|}{$50-90$} & \multicolumn{2}{|c|}{$30-62$} & \multicolumn{2}{|c|}{$50-70$} \\
\hline Year & 1976 & 1977 & 1976 & 1977 & 1981 & 1982 \\
\hline $\mathrm{CE}$ & 84.3 & 81.5 & 50.7 & 52.4 & 67.2 & 68.4 \\
\hline 10 Day CE & 91.5 & 94.7 & 87.3 & 41.9 & 71.8 & 68.7 \\
\hline
\end{tabular}


Table 7. Performance of the NITK model compared with that of Sahyadri.

\begin{tabular}{|c|c|c|c|c|}
\hline \multirow[b]{2}{*}{ Year/Catchments } & \multicolumn{2}{|c|}{ Performance of NITK model } & \multicolumn{2}{|c|}{ Performance of Sahyadri } \\
\hline & CE (daily) & CE (10-daily) & CE (daily) & $\mathrm{CE}$ (7-daily) \\
\hline \multicolumn{5}{|l|}{ Malathi } \\
\hline 1976 & 85.0 & 92.0 & 92.0 & 97.0 \\
\hline 1977 & 80.0 & 86.8 & 91.0 & 97.0 \\
\hline 1978 & 75.0 & 85.2 & 81.0 & 89.0 \\
\hline 1979 & 73.1 & 92.8 & 87.0 & 98.0 \\
\hline 1980 & 70.2 & 80.5 & 77.0 & 90.0 \\
\hline \multicolumn{5}{|l|}{ Hemavathi } \\
\hline 1976 & 51.9 & 90.2 & 88.0 & 93.0 \\
\hline 1977 & 50.9 & 48.7 & 86.0 & 96.0 \\
\hline 1978 & 63.2 & 73.9 & 69.0 & 81.0 \\
\hline 1979 & 74.9 & 77.1 & 85.0 & 89.0 \\
\hline 1980 & 85.0 & 84.7 & 89.0 & 93.0 \\
\hline \multicolumn{5}{|l|}{ Netravathi } \\
\hline 1981 & 64.7 & 73.3 & 74.1 & 74.4 \\
\hline 1982 & 68.9 & 69.6 & 78.2 & 81.7 \\
\hline 1983 & 75.1 & 82.9 & 86.1 & 92.4 \\
\hline 1984 & 70.6 & 85.2 & 83.4 & 86.9 \\
\hline 1985 & 50.5 & 70.4 & 85.5 & 85.8 \\
\hline
\end{tabular}

models were compared mutually. It was found that one of the reasons must be the inability of the NITK model to estimate continuously varying values of $\mathrm{CN}$. While actually on the field, the wetness condition varies continuously, $\mathrm{CN}$ is considered to vary only in lumps (change abruptly from one value to the next) in the model. Hence, it was decided to find out the kind of variation in $\mathrm{CN}$ that may be necessary to represent the surface runoff processes well in this region. For this purpose, the daily direct runoff values simulated by the model SAHYADRI were considered to be reliable and the CN necessary to estimate these values was estimated. To compute $\mathrm{CN}$, the curve number runoff expression was applied backwards using the daily values of rainfall and of DRO estimated by SAHYADRI. The method is discussed below.

Since the CN expression is,

$$
\mathrm{DRO}=(R F-C \cdot S)^{2} /(R F+S \cdot(1-C)) .
$$

$S$ can be obtained by developing and solving the quadratic equation

$$
a \cdot S^{2}+b \cdot S+c=0
$$

where,

$$
\begin{aligned}
& a=0.1 C \\
& b=-(2 C \cdot R F+(1-C) \cdot \mathrm{DRO}) \\
& c=R F^{2}-R F \cdot \mathrm{DRO} .
\end{aligned}
$$

The CN can be then obtained from $S$ as

$$
\mathrm{CN}=25400 /(S+254) .
$$

The values of $\mathrm{CN}$ for the data of the first two years were estimated for the three catchments using the above approach and the variations present in the series were studied. The temporal variations in $\mathrm{CN}$ are shown in figure 5. Here, the values of $\mathrm{CN}$ are plotted as a time series and as a 5 day moving average series, for a couple of cases. It is evident from these figures that the variation in $\mathrm{CN}$ is very large and is highly random. Mishra (2000) discussed the need for a continuously varying $\mathrm{CN}$ for simulating reliable values of daily runoff. However, the $\mathrm{CN}$ values generated by his model vary over a wide range, with almost the whole of the core monsoon period (July and August) exhibiting $\mathrm{CN}=100$ (or near that), for the optimum simulating conditions. This is rather conceptually inacceptable since it would mean zero infiltration or $100 \%$ saturation, a state which is too far from 

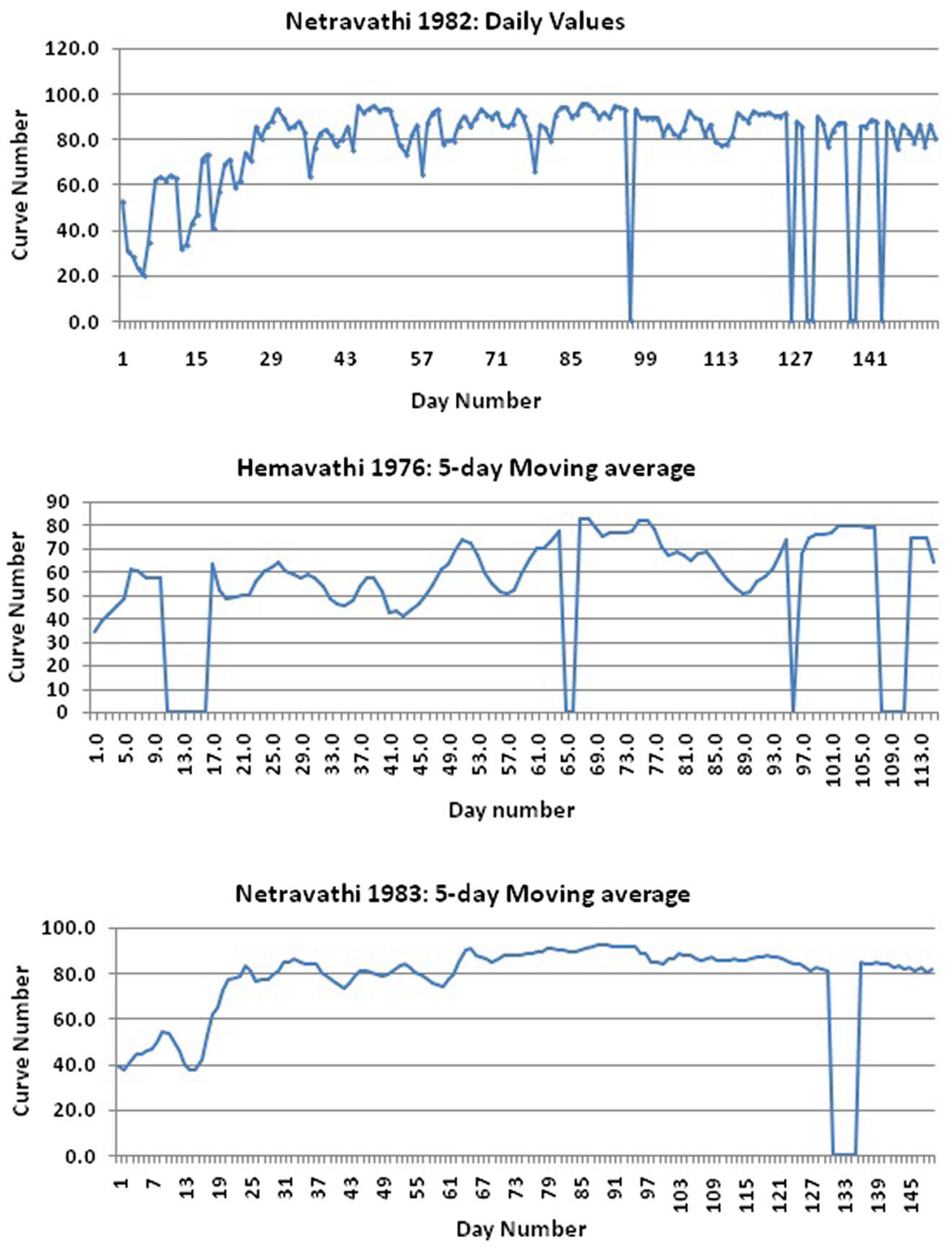

Figure 5. Values of CN necessary to simulate DRO in tune with the simulations of the model SAHYADRI (CN values presented as daily and 5-day moving average series). Note: Zero values for CN indicate days of runoff being greater than rainfall in excess of initial abstractions.

reality in an area where the infiltration capacities are of the order of 100 to $500 \mathrm{~mm} / \mathrm{h}$ and rainfall intensities are not very high (Putty and Prasad $2000 \mathrm{~b})$. The results from the present work, on the other hand, show that the $\mathrm{CN}$ needed to simulate well the direct runoff in any catchment would vary highly randomly between 40 and 90 . In fact, a careful study of the $\mathrm{CN}$ values estimated as above showed that the $\mathrm{CN}$ also depends to an extent on the daily rainfall magnitude. This is evident from figure 6, where $\mathrm{CN}$ is plotted against daily rainfall. It was also found that the correlation coefficient between $\mathrm{CN}$ and daily rainfall goes up to 0.7 in some cases. This establishes beyond doubt that the $\mathrm{CN}$ cannot be considered a constant, as far as this region is concerned, and goes to question the fundamental assumption in the $\mathrm{CN}$ model that just three values of $\mathrm{CN}$ would be sufficient to represent the variation in the wetness of the catchment. 

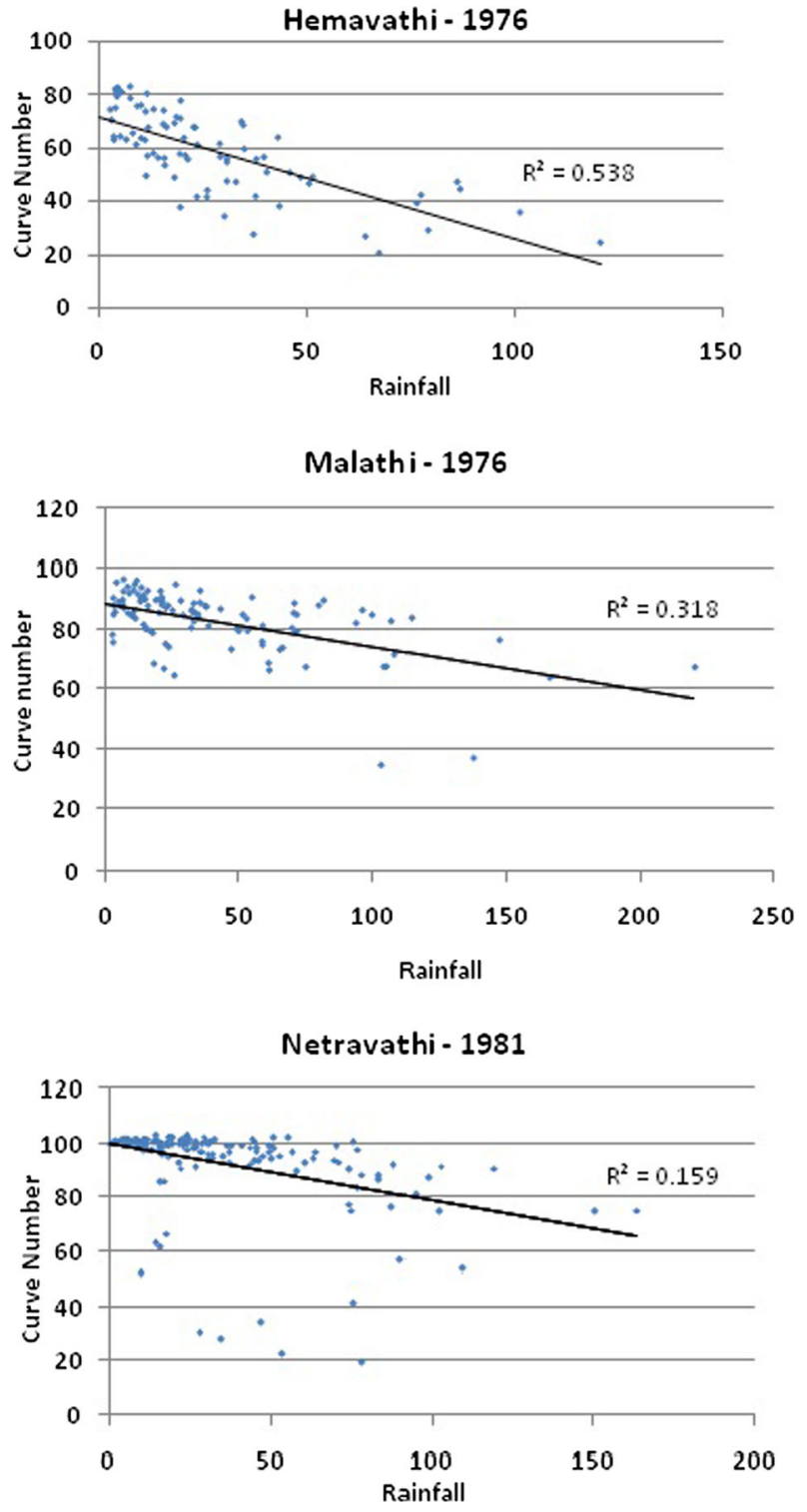

Figure 6. Daily values of CN estimated from SRO, plotted against rainfall.

\section{Discussion and conclusions}

The results above, where the simulating abilities of the NITK model were compared with those of SAHYADRI, go to show that the former model is not suitable for the region of Western Ghats. This fact means either that the model structure, formulated on the basis of the concepts regarding the runoff processes is not correct or that the method of choosing parameters is not proper. However, the fact that even with modifications to the model parameters, the simulating abilities are not much better means that the theoretical basis of the model may not be in coherence with the hydrological processes that characterize the region. The inferences from the sensitivity analysis and a study of the values of the $\mathrm{CN}$ required to estimate well as the surface runoff component establish that runoff in the region is not much related to the catchment characteristics that are used to estimate $\mathrm{CN}$ in the curve number method. Inferences from other models (Putty and Prasad 2000a; Putty 2009), show that streamflow in this region is dominated by subsurface flow, and that runoff generation is well explained by the variable source area theory (Ward 1984; Putty 2010). According to this theory, surface runoff is produced mainly from saturated source areas riparian to the streams and not from all over the catchment. The extent of the source areas, as well as the quantity of subsurface flow, are dependent on subsurface storages, which, in turn, depend on catchment recharge. Hence, characteristics of the surface matter little, except in small portions of the catchment that are devoid of thick vegetation or grass cover. The inferences from the present study further go to prove that the commonly used methods of yield and peak flood estimation, that relate runoff to the catchment characteristics, should not be used in areas like the Western Ghats. The present study emphasizes the need for further investigations to understand the factors that influence and control runoff processes in the region and for development of design procedures that suit the hydrological characteristics of the region.

\section{Acknowledgements}

This study is a part of the research project 'Impact of LULC Changes on Streamflow Regime - A case study of Netravathi Catchment, Karnataka', sponsored by ISRO, under its RESPOND Programme. The authors acknowledge the financial assistance provided for the project by ISRO. The authors also acknowledge the students of The National Institute of Engineering, Mysuru, who are involved in the studies concerning the project.

\section{References}

Aitken A P 1973 Assessing systematic errors in rainfallrunoff models; J. Hydrol. 20 121-136.

Anderson M G and Burt T P 1985 Modelling strategies; In: Hydrological Forecasting (eds) Anderson M G and Burt T P, John Wiley \& Sons Ltd.

Borugeon G 1989 Explanatory booklet on the reconnaissance soil map of forest area: Western Karnataka and Goa; French Institute, Pondicherry, India, 95p. 
Chow V T, Maidment D R and Mays L W 1988 Applied Hydrology; McGraw Hill Book Co. Ltd.

CUSU (Central unit for soil conservation), hydrology and sedimentation 1972 Handbook of Hydrology; Ministry of Agriculture, Government of India.

CWC (Central Water Commission) 2010 Development of hydrological design aids (surface water) under HP-II, State of the Art Report Revision: R2vi Document: 2009097/WR/REP-02, October 2010.

Darshan R 2016 Some studies on hydrological properties of soils in the upland areas of the Gundia Basin; Unpublished M.Tech dissertation, The National Institute of Engineering, Mysuru, India.

Geetha K, Mishra S K, Eldho T I, Rastogi A K and Pandey R P 2008 SCS-CN-based continuous simulation model for hydrologic forecasting; Water Resour. Manag. 22 165190, https://doi.org/10.1007/s11269-006-9149-5.

Hawkins M 1978 Runoff curve numbers in varying site moisture; J. Irrig. Drain. 4 392-396.

Hewlett J D and Hibbert R A 1967 Factors affecting the response of small watersheds to precipitation in humid areas; Proceedings of International Symposium on Forest Hydrology 1965, Pennsylvania State University, Pergamon Press, New York, pp. 275-289.

Mishra S K 1998 Long-term hydrologic simulation using SCS-CN method; Technical Report, National Institute of Hydrology, Roorkee, India.

Mishra S K 2000 SCS-CN based long term hydrologic simulation; Technical Reports, National Institute of Hydrology, Roorkee, India.

Mishra S K and Singh V P 1999 Another look at the SCS-CN method; ASCE J. Hydrol. Eng. 4(3) 257-264.

Mishra S K, Geetha K, Rastogi A K and Pandey R P 2005 Long-term hydrologic simulation using storage and source area concepts; Hydrol. Process. 19 2845-2861.

Mishra S K, Goel N K, Seth S M and Srivastava D K 1998 An SCS-CN-based long-term daily flow simulation model in a hilly catchment; International Symposium on Hydrology of Ungauged Streams in Hilly Regions for small Hydropower Development, New Delhi, India.

Mohan H S and Nair K S 1986 Hydro-climatic studies of the Western Ghats; Mausam 37(3) 329-331.

Nandagiri L 2002 Calibrating hydrological models in ungauged basins: Possible use of areal evapotranspiration instead of streamflows; Proceedings of the PUB Kick-off meeting held in Brasilia, IAHS Publications, 309p.

Nandagiri L and Shetty A 2009 Final report on the ISRO sponsored project - Integrating RS, GIS and hydrologic data for assessment of rural water sources (RESPOND Pr No $10 / 4 / 363)$.

Nandagiri L, Shetty A and Rajesh M V S 2004 A hydrologic model with identifiable parameters for predictions in ungauged basins; Proceedings of Workshop on
Predictions in ungauged basins for sustainable water resources planning and management, BITS, Pilani, pp. 43-48.

Pascal J P 1984 Wet evergreen Forests of the Western Ghats; French Institute, Pondicherry, India.

Prasad R and Malhotra K 1987 Some aspects of water resources in Karnataka; Department of Civil Engineering, Indian Institute of Science, Bengaluru, India.

Putty M R Y 2006 Salient features of the hydrology of the Western Ghats in Karnataka; In: Hydrology and watershed services in the Western Ghats of India (eds) Krishnaswamy J, Lele S and Jayakumar R, Tata-McGraw Hill Publ. Co. Ltd., New Delhi, India.

Putty M R Y 2009 A curve number based watershed model incorporating quick subsurface runoff, with applications in the Western Ghats, south India; ASCE J. Hydrol. Eng. 14(8) 876-881.

Putty M R Y 2010 Principles of Hydrology; IK Int. Publ. House Pvt. Ltd., New Delhi, India.

Putty M R Y and Prasad R 2000a Understanding runoff processes using a watershed model - A case study in Western Ghats in south India; J. Hydrol. 228 215-227.

Putty M R Y and Prasad R 2000b Runoff processes in head water catchments - An experimental study in Western Ghats, south India; J. Hydrol. 235 63-71.

Putty M R Y, Pradeep M P and Nagaraj M K 2007 Catchment response simulated by two variable source area models in a Western Ghat catchment; Proceedings WNCE'07 (Watershed Management and impact of Environmental charges on Water Resources), JNTU, Hyderabad, India.

Putty M R Y, Prasad V S R K and Ramaswamy R 2000 A study on the rainfall intensity pattern in Western Ghats, Karnataka; Proceedings of the Workshop on Watershed Development in Western Ghats, CWRDM, Kozikhode, Kerala, India, pp. 44-51.

Putty R Y 1994 The mechanisms of streamflow generation in the Sahyadri ranges (Western Ghats) of south India; Unpublished Ph.D. thesis, Indian Institute of Science, Bangaluru, India.

Putty R Y and Prasad R 1992 Application of a variable source area model for Western Ghats; Proceedings of International Symposium on Hydrology of Mountainous Areas, Shimla, India, pp. 439-450.

Putty R Y, Reddy P M and Reddy J V S 1996 Developing the curve number method into a variable source area watershed model; Proceedings of National Seminar HYDRO-96, Kanpur, India, pp. 53-57.

Subramanya K 2013 Engineering Hydrology; 4th edn, Tata McGraw Hill Publ. Co. Ltd., New Delhi, India.

Ward R C 1983 Hypothesis testing by modelling catchment response; J. Hydrol. 67 281-305.

Ward R C 1984 On the response of head water streams in humid areas; J. Hydrol. 74 171-189. 